\title{
Translational Medicine Research in Sub Saharan Africa - Challenges and Prospects
}

\author{
Chidiebube J. Ugwu
}

\section{ABSTRACT}

Translational medicine (TM) is a branch of medicine and research in which basic science research findings are implemented to solve clinical problems and it involves the generation of research questions from clinical problems - the so-called "bench to bedside and back to bench approach" [1]. Despite the vital importance of TM as would be seen in the course of this paper and the steps that other regions of the world have taken, and plan to take to bolster their already working TM sector, sub-Saharan Africa is yet to fully take the first few steps on the road to TM research [2], [3].

This situation of depending on the research findings from technologically advanced countries presents a lot of challenges as environment and genetics play a very important role in what kind of results are obtained [2]. This causes discrepancies in outcome/ inability to replicate study findings using the study methods and design applied by research that a clinical decision or recommendation was made.

Due to the workload on the health professionals, poor health care system, low interest in research, inadequate training and funding, and other factors that would be highlighted in this paper, the clinician is seldom able to lift his/her eyes from the present emergency to consider what may prove useful in the future. This state of affairs is also compounded by the fact that the fruition of TM research may take many years [4]. Some solutions include more efficient record keeping, more government support, improved research training among others. This paper aims to highlight the challenges of TM in sub Saharan Africa and further offer some practical and culturally adaptable solutions to these challenges.

Keywords: Translational Medicine, Translational Medicine Research, sub-Saharan Africa.

\section{INTRODUCTION}

Translational medicine (TM) is a branch of medicine and research in which basic science research findings are implemented to solve clinical problems and it involves the generation of research questions from clinical problems - the so-called "bench to bedside and back to bench approach" [1]. Thus, TM describes a progression of research in which basic science discoveries are used to treat or prevent human disease, and conversely, clinical observations are used to formulate research questions [1]. Recently, the scope of translational medicine is being expanded to include the application of these research breakthroughs to not just clinical practice but to population-focused healthcare issues including community health [1].

TM as a discipline is in its nascent stages when compared with traditional research. TM was birthed because of the need for effective clinical implementation of laboratory findings and fluent conversion of clinical needs into research questions. Despite the increased effort in
Submitted : January 25, 2021

Published : February 26, 2021

ISSN: 2593-8339

DOI: $10.24018 /$ ejmed.2021.3.1.692

\section{J. Ugwu*}

University of Nigeria Teaching Hospital, Enugu, Nigeria.

(e-mail: ugwuchidiebube15@gmail.com)

*Corresponding Author preclinical research, the output of new drugs has reduced significantly over the past years [5]. This specialty acts as a 2-way bridge between the bench, bedside, and recently the community.

However, some have argued that the development of any drug in modern medicine is an expression of a successful translation effort. But the introduction of TM is to align preclinical/basic science research into clinical applications [5].

Africa has the unenviable position of having a majority of the world's diseases (especially communicable diseases) and a distressingly low concentration of health care personnel [6]. Alarmingly, in spite of shouldering a quarter of the global burden of disease, sub-Saharan Africa has less than $1 \%$ of the global financial health resources and about $3 \%$ of the global health workforce [6], [7]. Also, of the more than 1.1 billion people that reside in Africa, more than $90 \%$ of them do not have access to affordable and safe surgeries [8]. Between 2004 and 2008, Africa despite having so much of the global burden of disease only contributed $1 \%$ of the total 
global clinical publications [9]. Such figures only serve to throw light on the dismal situation of things in the region under discussion. Furthermore, these figures mostly evaluate traditional clinical and basic science research without focusing on the relatively novel area of TM research.

Despite the vital importance of TM as would be seen in the course of this paper and the steps that other regions of the world have taken, and plan to take to bolster their already working TM sector, sub-Saharan Africa is yet to fully take the first few steps on the road to TM research [2], [3].

This situation of depending on the research findings from technologically advanced countries presents a lot of challenges as environment and genetics play a very important role in what kind of results are obtained [2]. This causes discrepancies in outcome/ inability to replicate study findings using the study methods and design applied by research that a clinical decision or recommendation was made.

Due to the workload on the health professionals and other factors that would be highlighted in this paper, the clinician is seldom able to lift his/her eyes from the present emergency to consider what may prove useful in the future. This state of affairs is also compounded by the fact that the fruition of TM research may take many years [4].

This paper aims to highlight the challenges of TM in sub Saharan Africa and further offer some practical and culturally adaptable solutions to these challenges.

\section{Global Scope of Translational Medicine}

\section{A. Global TM Research Challenges}

Globally, translational medicine has made great strides. Some of the major challenges widely identified include the cultural differences between basic scientists and clinicians, dearth of resources, and restrictive regulatory bodies [10].

Cultural differences arise from the fact that there is ineffective communication between the different camps of researchers and that there is a great difference in their training and remuneration [1].

The dearth of resources (human and material) are present in any setting, and manifests most when an insufficient amount of attention is paid internally or from external donors to the area of research of a given team leading to the allocation of fewer resources [1]. Physician-scientists are important in closing the distance between basic research and clinical medicine and reducing the time taken to translate basic research into relevant clinical applications. Interestingly, investigators with combined $\mathrm{MD}-\mathrm{PhD}$ degrees play an important part in TM. This is because, while they only represent $2.5 \%$ of medical school graduates each year, they oversee a third of NIH grants for research [11]. This situation is because by virtue of their training and qualifications, they occupy a strategic position in carrying out TM research.

Regulatory issues are a major barrier due to the sensitivity of the data generated on the bench or bedside. They include the ethics, ownership of intellectual patents, manufacturing regulations, supervisory body approvals like Food and Drug
Administration (FDA) and Medicines and Healthcare Regulatory Agency (MHRA) approvals, sponsorship as well as data management. These concerns are becoming increasingly complex with the rapid foray of medicine into new and controversial frontiers like genetic medicine and tissue engineering [4], [12].

The combination of these major challenges of cultural differences between basic scientists and clinicians, a dearth of resources, and restrictive regulatory bodies leads to the delay in the translation of research breakthroughs to clinical successes. This delay has been described by some as the "valley of death" [4].

One of the challenges internationally is the difficulty in sharing information within the private sector, academic circles, and government facilities. This has unfortunately led to the creation of gaps in knowledge and duplication of costly effort [13]. Other challenges of this lack of data sharing are the poor normalization of nomenclature and nonuniformity in the data generated by the various research centers [13].

Because of the long period between the identification of a research question to the generation of clinically usable information, the impact of TM is difficult to calculate. A study reviewed 30,000 publications, 15,000 each in the field of cancer, and cardiovascular medicine. The review was carried out by referencing citations and semantic network analysis. Their finding was that while there is some intersection between the publications by the clinical and basic science researchers, they are mostly polarized. In oncology research, the point of intersection was mostly hematopoietic tumors while in cardiovascular medicine is hypertension and atherosclerosis [14]. This shows that the anticipated collaboration between basic science and clinical researchers is not satisfactory [1], [14].

Another study conducted on the time required for a basic science research discovery to have clinical significance revealed that the time, referred to as 'translation lag' is almost always measured in years, averaging 20-24 years [11]. The study also observed the flow of citations between articles based on their Medical Subject Heading (MeSH) which has three major headings: Animal research (A), Cellular and genetic research $(\mathrm{C})$, and Human research $(\mathrm{H})$. The topics were triangulated and points of intersection were noted- $\mathrm{AH}, \mathrm{AC}, \mathrm{CH}$, and those containing the three, $\mathrm{ACH}$. Of all the citations in this mapping, $54 \%$ of the articles cited other articles in the same category, $36 \%$ of the articles cited articles in adjacent categories (e.g., AC citing $\mathrm{ACH}, \mathrm{H}$ citing $\mathrm{AH}$, or $\mathrm{AH}$ citing $\mathrm{A}$ ), and only $10 \%$ of the articles cited those in opposite categories (e.g., $\mathrm{H}$ citing $\mathrm{A}, \mathrm{C}$ citing $\mathrm{AH}$, or $\mathrm{AC}$ citing $\mathrm{H})$. Therefore, basic science research (A, AC, and $C$ ) seldom translates straight into $\mathrm{H}$ articles. Instead, it first passes through an intermediate stage $\mathrm{AH}, \mathrm{ACH}$, and $\mathrm{CH}$ ) [11]. Unfortunately, only a small proportion of basic research articles got translated into clinical application 'translational fraction' [11].

\section{B. Global TM Research Solutions in Various Stages of Implementation}

To further fuel collaboration and training of prospective TM researchers, various public and private agencies are currently offering grants both for training and research 
including the National Institutes of Health (NIH) and Clinical and Translational Science Awards (CTSA) in the US, and the National Institute of Health Research (NIHR) in the UK. Partnerships between different countries have also been developed seeing that the resource requirements for TM cannot be adequately met by one country. This led to the development of a pan European network of 11 major institutes, European Advanced Translational Research Infra Structure in Medicine (EATRIS) in 2012 [1].

Currently, there is an effort being made to ensure integration of information with data from genetic, biomarker, and clinical experiments being placed on online databases like Stanford Microarray Database, EBI Array Express, and NCBI GEO, etc. These databases permit bioinformaticians to use the data to perform further analyses [13], [15].

A further step taken was the initiation of partnerships between pharmaceutical companies and research centers to potentiate results [1]. For instance, AstraZeneca has created an alliance with the Karolinska Institute to search tissue banks for new proteomic biomarkers that may be markers of disease or increased risk. In the same vein, Gentris Corporation has partnered with academia in China to develop and validate novel genomic markers while Affymetrix and Leica Microsystems are developing complementary diagnostic tests for personalized medicine by significantly increasing the speed of professional DNA analyses. These partnerships serve to supply academic researchers with greater access to premium resources, which would stand them in good stead in understanding both medicine and disease with a view to finding novel therapies [1].

\section{EFFECT OF THE ENVIRONMENT OF SUB SAHARAN AFRICA ON TM RESEARCH}

Sub Saharan Africa has an environment almost completely at odds with the developed world whose strides in developing TM had been explored.

In sub Saharan Africa, survival is the keyword. Therefore, activities with immediate or near immediate results that do not promote survival are jettisoned. For a few visionaries, their ambition is cruelly crushed by the grim realities of poor funding, inadequate governmental support, or even resistance among other challenges.

One of the crises that brought into glaring focus the pitiable lack of trained cadre of TM researchers was seen during the 2014-2015 Ebola virus outbreak in West Africa. The lack of physician-scientists, epidemiologists, health care workers, well-equipped facilities among others accounted for the death toll from the outbreak [16], [17].

Some of the challenges that are encountered in TM research include;

\section{A. Existing Health Care System}

The existing health system in most sub Saharan countries is still in the infantile stages and has the potential to become developed. Very few doctors labor under an ever-increasing population. As mentioned sub-Saharan Africa has less than $1 \%$ of global financial health resources and about $3 \%$ of the global health workforce [6]. This situation is terrible because not only is there a severe shortage of manpower, even the existing workforce cannot be adequately recompensed for their provision/delivery of basic healthcare to a teeming populace [2]. In another African study, more than $62 \%$ of the participants experienced at least a single barrier due to personnel. These barriers according to this study mainly included inadequacies in research team leadership and commitment; and less implicated were clinical duties and workload [3]. To request this group of healthcare workers to do more in terms of TM research is indeed a tall order.

For a few that may think of a better tomorrow and want to engage with TM, there is a lack of facilities even for standard clinical practice. The clinician in this clime is besieged not just by inadequate structures that are often dilapidated but are under-equipped facilities. This creates a serious issue in the development of clinical research.

\section{B. Inadequate Record-Keeping and Filing}

Most patient data are manually kept in paper form. These documents are subject to the handling by doctors, nurses, laboratory scientists, janitors, and sometimes even the patient themselves. If the facilities are not safe from the elements or vermin, the information stored therein would most likely be lost partially or completely when there is exposure to these factors. Much more commonly, pages from the folder or the whole folder may get missing due to carelessness, misfortune, or an inefficient filing system.

The hoops required to be jumped to request for patient data may cause the sharp deterioration of interest of the researcher due to these possible hitches in information storage and retrieval [3]

\section{Poor Training}

Training, both for the basic science researcher or physician-scientist in sub Saharan Africa is fraught with challenges, ranging from untrained and unenthusiastic teachers (brain drain) to inadequacy of research of materials and facilities [2], [18]. These combine to create clinicians uninterested in research and basic scientists unmotivated to ply their trade. The medical training is also bereft of any joint medical-scientist degree programs that afford medical students basic research competencies to engage with this novel TM research.

\section{Lack of Interest in TM Research}

Poor training, funding, and facilities combine to create a general lack of interest in research, especially TM research [2].

\section{E. Inadequate Government Backing}

Inadequate funding and excess bureaucratic red tape for the most part stem from the lack of appreciation of the government of the need for TM research. This would lead to the allocation of funds to other areas [7].

\section{F. Excess Bureaucratic Red Tape/ Regulatory Approval}

The process of obtaining regulatory approval in some parts of sub Saharan Africa is a herculean endeavor due to a large amount of red tape to go through to get it. Such approval is a sine qua non for any research and if there are any issues with this checkpoint, the research would have to 
be terminated [3].

\section{G. A dearth of External Funding}

Financial constraint is a limitation that rings the death knell for many research ideas. These may range from the funds needed to carry out clinical research or the absence or inadequate remuneration for research work done on behalf of others [3], [19].

\section{H. The Prohibitive Cost of Instituting a Biomedical Research Laboratory}

The cost of setting up a biomedical research laboratory is outrageously expensive. This makes it impossible for an average scientist to foray into biomedical research unaided. As aid is not readily available in Africa and especially sub Saharan Africa, this point is also an important checkpoint that stifles TM research [2], [18].

\section{Inadequate Academic-Industrial Partnerships}

Because of the lack of emphasis on novel products in the African industrial sector, they are not very motivated to invest in groundbreaking research by academia. This produces the current situation where the research labs in the hospital are poorly funded and equipped and little is done there [2], [3].

\section{J. Poor Library Services}

There is an inadequacy in the provision of standard library services in sub Saharan Africa. This puts great strain on the effective progress of research as a major part of the research involves access to what others have done in similar fields. The inadequacy can mostly be traced to poor funding as both the hard copies of research publications and the subscriptions for online access both require funding [20].

\section{K. Poor Internet Facilities}

Adequate and cost-effective internet service is a cornerstone of any research endeavor. Africa unfortunately labors under erratic and very expensive internet coverage. Such is the inadequacy that sometimes even the best service available locally cannot guarantee optimum internet access and such 'high quality' service though defunct is usually prohibitively expensive [3].

\section{SOlUtions AND PROSPECTS OF TM RESEARCH IN SUB SAHARAN AFRICA}

While we are faced with a lot of challenges, we also have the opportunity of learning from advanced countries as they too went through most of these barriers to get to their current states. The developed world has made great strides and their experiences - their successes and failures can be used as a reference to develop a framework that can be used in the African indigenous environment. Though the problems in sub Saharan Africa are thematic, a lot of subtleties exist in each local setting, with varying representations of the above-mentioned challenges. Thus, the need for indigenous researchers and solutions tailored to the prevailing realities in their environment.

It would be folly to blindly copy the process of the development of TM in developed climes, but their experience can enable us to avoid a great number of pitfalls.
These experiences would also provide a lot of inspiration that may not occur to an African clinician or scientist due to the peculiarities of his/her training or practice. For instance, in the area of cancer research and immunotherapy, immunotherapy has been found to only work in a few percent of those it is used with high toxicity [21].This information should likely influence the emphasis of immunotherapy research in Africa.

A factor that would promote TM research is the use of simple data collection tools [3]. Some of the issues facing health care can be assessed with the use of concise, simple questionnaires and other data collection tools

The government would need to be sensitized to the importance of TM research. If this can be done effectively, requisite funds would be allocated to TM researches [7]. This step can only be taken by those who understand the political terrain in the specific sub Saharan African countries and know how to bring pressure to bear on the government to produce change.

Despite the limitations of funding, more than $90 \%$ of respondents in an African study replied that they would be open to engaging in unpaid research work in the future [3]. This goes to show that despite the strain of work and poor remuneration, African clinicians are willing to engage in research.

This willingness to engage in research can be bolstered by ensuring that medical students are exposed to research especially TM research as undergraduates. This would ensure that some develop a passion for this neglected field. Also, career paths for physician-scientists should be provided ensuring reasonable remuneration and opportunities for advancement. This framework should allow them the liberty to engage in research without worrying about sustenance [2]. This is highly vital as the profitability (translation into clinical application) of even successful basic scientific research takes about 20 -24 years [11].

As Africa contributes a large percentage of global disease, committed research from her clinicians and basic scientists would go a long way in bridging the 10/90 gap in research [3]. This gap is that less than $10 \%$ of the global funding for research is used for research into diseases that affect more than $90 \%$ of the global populace [22]. This fact is attractive to drug developers as more population equals more consumers. And dedicated indigenous TM researchers would ensure a steady stream of practicable novel therapeutic options to a sizeable proportion of the world's population.

\section{CONCLUSION}

TM research endeavors must be locally relevant, yet globally sufficient and standardized to attract foreign investors and industrial partnership. One must ask; what does the sub Saharan African researcher have to contribute to a foreign funder? What the grantor offers may be funds, equipment, or knowledge. Granted the TM researcher is beset by troubles ranging from an infantile health system to poor data retrieval capabilities, but there are also prospects that the unique sub Saharan African environment presents. There are also partnership opportunities, whether, for 
altruism or profit, these opportunities do exist and the sub Saharan African TM researcher's value would only increase when he/she is well acquainted with the successes and pitfalls already recorded in their chosen field of TM and is motivated to positively impact population health through TM science.

\section{ACKNOWLEDGMENT}

The author extends sincere thanks to Drs Charles Okere and Stanley Ozogbo, for their invaluable assistance in the review of this paper.

\section{REFERENCES}

[1] Homer-Vanniasinkam S, \& Tsui J (2012). The Continuing Challenges of Translational Research: Clinician-Scientists' Perspective. Cardiology Research and Practice Journal, Volume 2012, doi:10.1155/2012/246710.

[2] Adefuye AO, Adeola A \& Bezuidenhout J (2018). The physicianscientists: rare species in Africa. Pan African Medical Journal. 2018; 29:8 doi:10.11604/pamj.2018.29.8.13239.

[3] Conradie A, Duys R, Forget P \& Biccard BM (2018). Barriers to clinical research in Africa: a quantitative and qualitative survey of clinical researchers in 27 African countries. British Journal of Anesthesia, 121 (4): 813e821.

[4] Butler, D. (2008). Translational research: crossing the valley of death. Nature, 453(7197): 840-842.

[5] Wehling M (2008). Translational medicine: science or wishful thinking? Journal of Translational Medicine, 6:31.

[6] Anyangwe SC, Mtonga C. Inequities in the global health workforce: the greatest impediment to health in sub- Saharan Africa. Int $\mathbf{J}$ Environ Res Publ Health 2007; 4: 93e100.

[7] Cochrane G, Manville C. Probing the Barriers to Conducting Clinical Research in Sub-Saharan Africa 2014. Accessed on 15 October 2020.

[8] Meara JG, Leather AJ, Hagander L, et al. Global surgery 2030: evidence and solutions for achieving health, welfare, and economic development. Lancet 2015; 386:569e624.

[9] Adams J, King C \& Hook D (2010). Global research report Africa 2010. Evidence, Thomson Reuters. Available from: http://researchanalytics.thomsonreuters.com $/ \mathrm{m} / \mathrm{pdfs} /$ globalresearchrep ort-africa.pdf.

[10] Hait, W. N. (2005). Translating research into clinical practice: deliberations from the American Association for Cancer Research. Clinical Cancer Research, 11(12): 4275-4277.

[11] Weber G (2013). Identifying translational science within the triangle of biomedicine. Journal of Translational Medicine, 11:126.

[12] Michael D (2020). Complications in Translational Research. Translational Medicine. 10:209. DOI:10.24105/2161-1026.10.209.

[13] Szalma et al (2010). Effective knowledge management in translational medicine. Journal of Translational Medicine 2010, 8:68. Available: http://www.translational-medicine.com/content/8/1/68.

[14] Jones et al (2011). Detection and characterization of translational research in cancer and cardiovascular medicine. Journal of Translational Medicine. 9:57.

[15] Parkinson H, et al (2009). ArrayExpress update-from an archive of functional genomics experiments to the atlas of gene expression. Nucleic Acids Res 2009, 37:D868-72.

[16] Mbonye AK, Wamala JF, Nanyunja M, Opio A, Makumbi I, Aceng JR (2014). Ebola viral hemorrhagic disease outbreak in West Africalessons from Uganda. Afr Health Sci. 14(3): 495-501. 1968.

[17] Brechot C. (2015). Train Africa's scientists in crisis response: to prevent future epidemics, a new international effort must boost West Africa's scientific and public-health capacity. Nature. 524(7563): 7-8.

[18] Kokwaro G, Kariuki S (2001). Medical research in Africa: problems and some solutions. Malawi Medical Journal. Sep; 13(3): 40.

[19] van Hoving DJ, Brysiewicz P (2017). African emergency care providers' attitudes and practices towards research. African Journal of Emergency Medicine; 7: 9e14.

[20] Tiwari R (2000). Internet and library services. Library Herald. 38(3\&4): 164.

[21] Masucci et al (2017). The need for a network to establish and validate predictive biomarkers in cancer immunotherapy. Journal of Translational Medicine. 15:223.
[22] Kilama W (2009). The 10/90 gap in sub-Saharan Africa: Resolving inequities in health research. Acta Tropica, 112(1): S8- S15. 